\title{
Spin in the abstracts of randomized controlled trials in periodontology and oral implantology: A crosssectional analysis
}

DOI:

10.1111/jcpe. 13340

\section{Document Version}

Accepted author manuscript

Link to publication record in Manchester Research Explorer

Citation for published version (APA):

Wu, X., Yan, Q., Fang, X., Hua, F., Shi, B., \& Tu, Y. (2020). Spin in the abstracts of randomized controlled trials in periodontology and oral implantology: A crosssectional analysis. Journal of Clinical Periodontology.

https://doi.org/10.1111/jcpe.13340

\section{Published in:}

Journal of Clinical Periodontology

\section{Citing this paper}

Please note that where the full-text provided on Manchester Research Explorer is the Author Accepted Manuscript or Proof version this may differ from the final Published version. If citing, it is advised that you check and use the publisher's definitive version.

\section{General rights}

Copyright and moral rights for the publications made accessible in the Research Explorer are retained by the authors and/or other copyright owners and it is a condition of accessing publications that users recognise and abide by the legal requirements associated with these rights.

\section{Takedown policy}

If you believe that this document breaches copyright please refer to the University of Manchester's Takedown Procedures [http://man.ac.uk/04Y6Bo] or contact uml.scholarlycommunications@manchester.ac.uk providing relevant details, so we can investigate your claim.

\section{OPEN ACCESS}


DR. FANG HUA (Orcid ID : 0000-0002-2438-5924)

PROF. YU-KANG TU (Orcid ID : 0000-0002-2461-474X)

Article type : Original Article Clinical Periodontology

\title{
Spin in the abstracts of randomized controlled trials in periodontology
} and oral implantology: A cross-sectional analysis

\author{
Running title: Presence of spin in trial abstracts
}

Xinyu $\mathrm{Wu}^{1,2^{+}}$, Qi Yan ${ }^{1,2^{+}}$, Xiaolin Fang ${ }^{1}$, Fang Hua ${ }^{3,4^{*}}$, Bin Shi ${ }^{1,2^{*}}$, Yu-Kang $\mathrm{Tu}^{5}$

\section{Author affiliations}

1. Hubei-MOST KLOS \& KLOBM, School \& Hospital of Stomatology, Wuhan University.

2. Department of Oral Implantology, School \& Hospital of Stomatology, Wuhan University.

3. Center for Evidence-Based Stomatology, School \& Hospital of Stomatology, Wuhan University.

4. Division of Dentistry, School of Medical Sciences, Faculty of Biology, Medicine and Health, The

University of Manchester, Manchester Academic Health Science Centre.

5. Institute of Epidemiology and Preventive Medicine, College of Public Health, National Taiwan This article has been accepted for publication and undergone full peer review but has not been through the copyediting, typesetting, pagination and proofreading process, which may lead to differences between this version and the Version of Record. Please cite this article as doi: $10.1111 /$ jepe. 13340

This article is protected by copyright. All rights reserved 
University.

${ }^{+}$Xinyu Wu and Qi Yan contributed equally to this work.

\section{${ }^{*}$ Corresponding authors}

Fang Hua, Center for Evidence-Based Stomatology, School \& Hospital of Stomatology, Wuhan University, Luoyu Rd 237, Wuhan 430079, China

Tel: +86 2787686226 ; Fax: +86 2787873260

Email: huafang@whu.edu.cn

Bin Shi, Department of Oral Implantology, School \& Hospital of Stomatology, Wuhan University, Luoyu Rd 237, Wuhan 430079, China

Tel: +8627 87686222; Fax: +862787873260

Email: shibin_dentist@whu.edu.cn

\section{Acknowledgements}

This work was supported by the National Clinical Key Specialties Construction Project, National Health Commission of China (No. [2013]544), the China Postdoctoral Science Foundation (No. 2018M630884), and the Wuhan Young and Middle-aged Medical Talents Training Program (No. [2019]87).

This article is protected by copyright. All rights reserved 


\section{Author contribution}

Study conception: FH. Study design: XW, QY, XF, FH, BS, YKT. Literature searches: XW, QY. Data collection: XW, QY, XF. Data analysis: XW, QY, FH. Data interpretation: FH, BS, YKT. Manuscript drafting: XW, QY. Critical revision of the manuscript: XF, FH, BS, YKT. Approval of final version: All authors.

\section{Conflict of interest statement}

The authors declare that they have no conflict of interest.

This article is protected by copyright. All rights reserved 


\section{Abstract}

Objectives: To investigate the presence and characteristics of spin (a distorted interpretation to make research findings seem favorable) in abstracts of randomized controlled trials (RCTs) in periodontology and oral implantology, and to explore its associated factors and influence on the subsequent literature.

Materials and methods: PubMed was searched to identify recent RCTs in periodontology and oral implantology, whose primary outcome was non-significant. Spin in abstracts was assessed and categorized according to pre-determined spin strategies. The associations between study characteristics and the presence / severity of spin were analyzed using multivariable logistic regressions.

Results: 196 abstracts were included, 137 (69.9\%) of which had spin. 57 (29.1\%) abstracts had spin in the Results Section, 126 (64.3\%) had spin in the Conclusion Section. The main spin strategies in the Results and Conclusion Sections were focusing on secondary outcomes (16.3\%) and focusing on within-group comparisons (28.6\%), respectively. The presence of spin was associated with number of centers (OR=0.28, 95\% Cl: $0.11-0.73 ; p=0.009)$ while its severity was associated with topic (OR=0.24, 95\% $\mathrm{Cl}: 0.08-0.70 ; p=0.009)$.

Conclusions: The frequency of spin is relatively high among published RCT abstracts in 
periodontology and oral implantology. Findings reported in these abstracts need to be interpreted with caution.

Key words: spin; periodontology; oral implantology, randomized controlled trial.

This article is protected by copyright. All rights reserved 


\section{Clinical significance}

Scientific rationale for study: Spin is a distorted interpretation in study abstract that makes research findings seem favorable and could mislead readers' clinical decision making.

Principal findings: Spin is common in RCT abstracts in periodontology and oral implantology. Abstracts with spin usually focused on secondary outcomes in the Results Section and within-group comparisons in the Conclusion Section. In addition, abstracts with spin had further scientific influence on citing articles.

Practical implications: Researchers, editors and peer reviewers should make concerted efforts to improve abstract reporting and avoid spin. Clinicians should not base their decision making on abstracts alone.

This article is protected by copyright. All rights reserved 


\section{Introduction}

Randomized controlled trials (RCTs) hold high position in the evidence pyramid of Evidence-Based Medicine (Haynes, Devereaux, Guyatt, 2002) and are the basis for systematic reviews and meta-analyses. In addition, RCT is an optimal study design to compare the efficiency of clinical interventions by minimizing the confounding bias between groups (Brignardello-Petersen, Carrasco-Labra, Glick, Guyatt, Azarpazhooh, 2015). Critical appraisal of the full-texts of RCTs could inform readers of the research scenario and outcomes to appropriately apply clinical evidence (Brignardello-Petersen, Carrasco-Labra, Glick, Guyatt, Azarpazhooh, 2014).

Abstracts of RCTs provide a quick overview of the trials for readers to decide whether to read the full-texts. For many clinicians, clinical decision making is based solely on RCT abstracts due to a lack of time or the limited access to full-texts. Although the context of abstract reporting has been standardized (Hopewell et al., 2008), researchers might make slight modifications to the presentation of the research findings in abstracts and influence readers' decision making. For example, readers could be misled when statistically non-significant difference between two treatments are interpreted as being equivalent (Carrasco-Labra, Brignardello-Petersen, Azarpazhooh, Glick, Guyatt, 2015). Such misleading results could then be cited in subsequent articles and accessed by a wider range of readers. Since details of research findings could not be provided due to the limited space of an abstract, this further increases the impact of the distorted interpretation.

Spin, in biomedical research, means a distorted interpretation of study results or conclusions, 
intentionally or subconsciously, to make the results or conclusions more favorable, especially when the results are statistically non-significant (Boutron, Dutton, Ravaud, Altman, 2010). Trial abstracts with spin tend to give readers the impression that the experimental therapies have larger beneficial effects, and readers are therefore more likely to read the full-texts (Boutron et al., 2014). It is reported that spin exists in $60.5 \%$ RCT abstracts with non-significant primary outcomes in biomedical literature (Chiu, Grundy, Bero, 2017) and $30.7 \%$ in dental research(Roszhart, Kumar, Allareddy, Childs, Elangovan, 2019). The association between the presence of spin and study characteristics, such as sources of funding or the presence of international collaboration, remains unclear (Cooper et al., 2018; Khan et al., 2019; Roszhart et al., 2019).

Periodontology and oral implantology are popular subjects in dentistry and attract much scientific and online attention (Garcovich, Ausina Marquez, Adobes Martin, 2020; Warren, Patel, Boyd, 2019). In addition, the main findings of most RCTs in periodontology and oral implantology are non-significant (Kiriakou, Pandis, Madianos, Polychronopoulou, 2014), among which spin is more likely to exist. Different aspects of RCT reporting have been assessed in periodontology and oral implantology (Kumar, Mohammad, Vora, Kar, 2018; Lieber, Pandis, Faggion, 2020; Sendyk, Rovai, Souza, Deboni, Pannuti, 2019). However, to our knowledge, the existence and characteristics of spin in abstracts of RCTs in periodontology and oral implantology have not been studied. Furthermore, the scientific influence of the spin in abstracts on subsequent citing articles has not been explored.

Thus, the aims of this study were 1) to assess and describe spin in the abstracts of RCTs with 
non-significant primary outcome(s) in the fields of periodontology and oral implantology; 2) to investigate study characteristics associated with the presence and severity of spin in abstracts; and 3) to explore the scientific influence of spin in abstracts on subsequent citing articles.

\section{Materials and methods}

\subsection{Study selection}

RCTs in periodontology and oral implantology published during 2017-2019 were identified by searching PubMed (search strategy described in Appendix Table 1). As pre-determined, Only RCTs with statistically non-significant primary outcomes were included. RCTs without clearly defined primary outcome, with significant primary outcome, or equivalence or inferiority trials were excluded (Boutron et al., 2010). Two authors (X.W. and Q.Y.) conducted the study selection independently and in duplicate. Any disagreement was resolved through discussion with two experts (F.H. and B.S.).

To determine the primary outcome(s) of each included RCT, the following rules were developed a priori (Austin et al., 2019; Boutron et al., 2014; Roszhart et al., 2019) and used according to their order in the list:

1. Explicitly reported primary outcome(s) in the full-text;

2. The outcome(s) used in sample size calculation;

3. Explicitly reported primary outcome(s) in clinical trial registration;

4. Outcome(s) reported in the Results Section and in consistent with the primary / main research objective.

This article is protected by copyright. All rights reserved 


\subsection{Data extraction}

The following information of included studies were recorded by two authors (X.W. and Q.Y.) independently and in duplicate, with all discrepancies resolved through discussion: journal name, publication year, article title, PubMed ID, trial registration number (if available), research topic (periodontology vs. oral implantology), geographical origin, type of institution (university vs. others), top dental school according to the QS ranking (Quacquarelli Symonds, 2020), multiple affiliations, international collaboration, funding status (funded by industries, vs. other sources), number of centers, number of treatment arms, and primary outcome item(s).

\subsection{Assessment of spin}

The presence of spin was assessed in each included abstract and the location and content of spin was documented. To calibrate examiners, an internal pilot study was performed. Three authors (X.W., Q.Y. and X.F.) carried out independent assessments in rounds of 15 randomly selected abstracts, until strong agreement was reached (Fleiss kappa statistics, $k \geqslant 0.90$ ) (Fang et al., 2020). All discrepancies were resolved through discussion with two experts (F.H. and B.S.).

Thereafter, one author (X.W.) assessed all of the remaining abstracts. Briefly, spin was considered when an abstract 1 ) focused only on statistically significant results (such as those arising from within group comparisons, secondary outcomes or subgroup analyses), 2) interpreted non-significant results as showing equivalent effect, 3) claimed non-significant results as efficacy or beneficial outcomes. Strategies of spin were categorized according to a previous 
study (Boutron et al., 2010).

\subsection{Scientific influence of spin}

To assess the scientific influence of spin in abstracts, articles citing those RCTs with spin in abstracts were identified from a Web of Science (in March 2020) search. Articles citing the RCTs were evaluated. The frequencies of inappropriate citation were recorded. As determined a priori, when citing the RCT identified with spin, if an article 1) interpreted non-significant results as significant, 2) claimed efficacy or benefit of treatment therapies based on non-significant results, or 3) described irrelevant topics, the article was considered as inappropriate citation. When multiple types of inappropriate citations coexisted in one citing article, all of them were recorded.

\subsection{Statistical analysis}

SPSS version 25 (IBM Corp, Armonk, NY, USA) was used for statistical analysis. The proportion of abstracts by study characteristics was calculated and described. The association between the presence and severity of spin and specific study characteristics, namely research topics, top dental schools, international collaboration, funding status and number of centers (Chen et al., 2019; Khan et al., 2019; Roszhart et al., 2019) were explored with multivariable logistic regression analyses. Firstly, for factors associated with the presence of spin, all abstracts were included in the multivariable logistic analysis using the presence of spin (with spin vs. no spin) as dependent variable. Secondly, for factors associated with the severity of spin, only abstracts with 
spin were included, using the severity of spin ( $\leq$ two spin strategies as minor spin vs. $\geq$ three spin strategies as severe spin) as dependent variable. The goodness of fit was tested using the Hosmer \& Lemeshow test. Statistical significance was defined as $p<0.05$.

\section{Results}

\subsection{Study characteristics}

A total of 196 RCT abstracts were included in this study (Figure 1, Appendix Table 2). Sources of primary outcomes included full-text methods (55.6\%), trial objectives (16.3\%), sample size calculation (17.9\%), and trial registration (10.2\%). Included RCTs were mainly published in specialty journals such as Clinical Oral Implants Research (17.3\%), Clinical Implant Dentistry and Related Research (15.3\%) and International Journal of Oral Implantology (11.7\%). Majority of the RCTs were conducted in universities (93.9\%), comparing two arms (91.3\%), and conducted in a single center (87.8\%). Most RCTs were on oral implantology $(75.0 \%)$ and conducted with multiple affiliations (63.8\%). Details are listed in Table 1.

\subsection{Spin assessment}

Of the 196 included RCTs, spin was identified in 137 RCT abstracts (69.9\%), including 36 RCTs published in 2017, 52 RCTs published in 2018, and 49 RCTs published in 2019. Spin was identified in the Results Section of 57 abstracts (29.1\%) and in the Conclusion Section of 126 abstracts (64.3\%), respectively.

The identified strategies of spin are listed in Table 2. Spin was found in the Results Section of 
32 abstracts (16.3\%), which all focused on within and/or between-group secondary outcomes. With regard to spin strategies found in the Conclusion Section, 56 abstracts (28.6\%) focused on within-group assessment, 38 abstracts (19.4\%) had spin due to focusing only on statistically significant between-group results (for other primary outcomes, secondary outcomes or subgroup analyses), and 20 abstracts (10.2\%) showed spin due to the claim of equivalence or non-inferiority for statistically non-significant results.

\subsection{Factors associated with spin}

For factors associated with presence of spin, all 196 RCT abstracts were included in a multivariable logistic regression analysis. Multi-center RCTs were significantly less likely to present spin in abstracts $(\mathrm{OR}=0.28,95 \% \mathrm{Cl}: 0.11-0.73 ; p=0.009)$. For factors associated with the severity of spin, 137 RCT abstracts were included. RCTs in oral implantology were associated with less severity of $\operatorname{spin}(\mathrm{OR}=0.24,95 \% \mathrm{Cl}: 0.08-0.70 ; p=0.009)$. Details are listed in Table 3.

\subsection{Scientific influence of spin}

In the Web of Science search, those 137 RCTs with spin in abstracts received a total of 516 citations (median, 2; interquartile range, 1-4). Fifty-nine RCTs with no spin in abstracts received 90 citations (median, 0; interquartile range, 0-2). According to Wilcoxon rank sum test, the citation counts of RCTs with and without spin were significantly different $(p<0.001)$.

Twenty-four RCTs received 34 inappropriate citations. Thirteen RCTs published in 2017 received 20 inappropriate citations. Ten RCTs published in 2018 received 13 inappropriate 
citations. One RCT published in 2019 received one inappropriate citation. That is, for RCTs with spin in abstracts, the mean frequency of inappropriate citation was $0.56,0.25$ and 0.02 , in 2017 , 2018 and 2019, respectively. Of the 34 inappropriate citations, 18 citations (52.9\%) interpreted non-significant results as significant, 12 citations (35.3\%) described irrelevant topics, and four citations $(11.8 \%)$ claimed efficacy or recommended using the treatments based on non-significant results.

\section{Discussion}

To our knowledge, this is the first study assessing spin in RCT abstracts in periodontology and oral implantology. Factors associated with the presence and severity of spin in abstracts were analyzed. In addition, the scientific influence of spin in abstracts was explored. In the present study, spin was identified in $69.9 \%$ abstracts. Abstracts with spin in the Results Section was mainly focusing on secondary outcomes while abstracts with spin in the Conclusion Section was mainly focusing on within-group comparisons. Multi-center RCTs were less likely to present spin in abstracts. RCTs in oral implantology were associated with less severity of spin. Abstracts with spin had adverse scientific influence on subsequent publications.

The abstracts of RCTs with non-significant primary outcomes were more likely to present spin and thus were chosen as a representative sample of this study. In the first study assessing spin in RCTs in biomedical research, it was reported that spin was more prevalent in abstracts than in full-texts (Boutron et al., 2010). A systematic review (Chiu et al., 2017) reported that the presence of spin was more frequent in abstracts of superiority RCT with non-significant primary

This article is protected by copyright. All rights reserved 
outcome $(60.5 \%)$ than that in all categories of trials (56.8\%). Recently, studies in various subjects have reported a rate of spin in abstracts to be from $23.2 \%$ to $70 \%$ (Cooper et al., 2018; Kinder, Weaver, Wayant, Vassar, 2019). In addition, in leading dental journals, spin was presented in 30.7\% RCT abstracts with non-significant primary outcome (Roszhart et al., 2019). In the present study, spin was identified in $69.9 \%$ of RCT abstracts in periodontology and oral implantology, which was higher than that reported in most previous studies. The difference among studies might be explained by different subjects, some bias in assessment among authors, and sources of RCTs (from PubMed search or leading journals).

In this study, the proportion of abstracts with spin in the Conclusion Section (64.3\%) was twice higher than the proportion of abstracts with spin in the Results Section (29.1\%). Previous studies did not identify such dramatic difference in surgery (in which the proportion of abstracts with spin in the Results and Conclusion Sections were $17 \%$ and $27 \%$, respectively) (Arunachalam, Hunter, Killeen, 2017), otolaryngology (53\%, 57\%) (Cooper et al., 2018), anaesthesiology (10.1\%, 19.6\%) (Kinder et al., 2019), obesity (37.8\%, 24.4\%) (Austin et al., 2019), and cardiovascular diseases (41\%, 48\%) (Khan et al., 2019). The high prevalence of abstracts with spin in the Conclusion Section indicated that readers should interpret the conclusion presented in the abstracts with caution.

The major spin strategy in the Results Section of abstracts was focusing on secondary outcomes, including within- and between-group comparisons (32 abstracts, 16.3\%). This was in accordance with previous studies (Cooper et al., 2018; Kinder et al., 2019). However, in the previous study assessing spin in dentistry, it was reported that only two of 75 RCTs with 
non-significant primary outcomes focused on secondary outcomes in abstract reporting (Roszhart et al., 2019). Primary outcome is the most important result and the basis of sample size calculation. Thus, focusing on secondary outcomes reflects a misunderstanding of RCT results (Cooper et al., 2018). According to the CONSORT, primary outcome is the most important outcome measure and should be explicitly stated (Moher, Schulz, Altman, 2001). In abstracts, for primary outcome, results for each group and the estimated effect size and their precision should be reported. For abstract not reporting primary outcome, the secondary nature of other outcomes should be indicated (Hopewell et al., 2008).

Abstracts with spin in the Conclusion Section mainly focused on within-group comparisons (56 abstracts, $28.6 \%$ ), such as "both groups showed significantly improvement in clinical parameters". By emphasizing the within-group comparisons, an RCT was interpreted as a before-after study, showing beneficial outcomes of a treatment. However, the superiority of an RCT design is to make comparisons of treatments and detect whether there was any difference. In addition, the abstracts with spin in the Conclusion Section usually focused only on significant between-group results (38 abstracts, 19.4\%) and claimed the equivalence of treatment arms based on non-significant primary outcomes (20 abstracts, 10.2\%). Presence of spin weakens the importance of primary outcomes, distorts the initial aims of trials and misleads readers in clinical decision making (Boutron et al., 2014). Thus, for scientific researchers, abstract reporting should be direct, clear and transparent. For readers, clinical decision making should base on full-texts.

Previous studies have explored the association between spin in abstracts and various factors, including industry funding, the number of treatment arms, reporting of trial registration, journal

This article is protected by copyright. All rights reserved 
impact factor, international collaboration, article citations, and the conflict of interest disclosures (Cooper et al., 2018; Khan et al., 2019; Roszhart et al., 2019). Only Khan et al (2019) reported a significant negative correlation between presence of spin in abstracts and article citations. They explained that researchers might intentionally or subconsciously underreport funding relationships so that an association between financial funding and spin in abstracts could not be identified. In this study, multivariable logistic regression analyses showed that single-center RCTs were more likely to present spin in abstracts, and RCTs in periodontology were more likely to have severe spin. However, no evidence of a difference was found between RCTs funded by the industry and other RCTs funded by other sources, which is in line with the findings of several previous studies regarding spin (Jellison et al., 2019; Khan et al., 2019; Roszhart et al., 2019).

Scientific influence of spin was assessed by checking citations of included RCTs with spin in abstracts. In this study, the mean frequency that an RCT with spin in abstract was inappropriately cited was low but showed an increasing trend with time. In addition, most inappropriate citations were interpreting non-significant results as significant (18 of 34). Such errors in citations could be replicated in further research, exert adverse influence over time (Greenberg, 2009), and lead to research waste (Almaqrami, Hua, Liu, He, 2020). Inappropriate citations could be explained by inadequate appraisal of reference articles, which lead to ignorance of available evidence, hinder scientific research progress and influence clinical decision making (Fergusson, 2009). Thus, for scientific authors, citing articles accurately and adequately is necessary. For readers, a scientific article should be critically appraised before being applied in clinical decision making. However, the present study failed to identify any relationship between spin in abstracts and inappropriate 
citations. This could be partially explained by a limited observational period. Whether abstract spin has influence on further citations and the extent of such influence remains to be discussed in future research.

The strengths of this study included that 1) multivariable logistic regression analyses were performed to explore certain study characteristics associated with spin, and 2) the scientific influence of spin in abstracts was investigated. One limitation of our study is that only RCT abstracts with non-significant primary outcomes were included, which means that our findings may not apply to all RCT abstracts in the fields. However, this approach has been widely used among previous studies assessing spin (Boutron et al., 2014; Boutron et al., 2010; Khan et al., 2019; Roszhart et al., 2019), as there is empirical evidence that spin is more common among abstracts of trials with non-significant primary outcome(s) (Chiu et al., 2017). In addition, an assessment of the reporting quality of included RCTs and RCT abstracts was not included in the present study. Several previous studies in the fields of periodontology and oral implantology had performed such assessments, exposed relevant inadequacies and provided helpful recommendations (Kiriakou et al., 2014; Kloukos, Papageorgiou, Doulis, Petridis, Pandis, 2015; Kumar et al., 2018; Lieber et al., 2020; Sendyk et al., 2019). Therefore, in the present study, we decided a priori to focus on the issue of spin in these fields, which to our knowledge had not been well explored. Furthermore, our study did not investigate to what extent spin can influence the editors' and peer reviewers' attitudes and clinicians' decision making, which could be the focus of future research.

This article is protected by copyright. All rights reserved 


\section{Conclusions}

Among RCT abstracts in the fields of periodontology and oral implantology, spin exists commonly in a variety of different strategies. Editors, peer reviewers and authors should be aware of the misleading scientific influence of spin and make efforts to avoid them. Dental practitioners need to interpret findings reported in abstracts with caution, and base their clinical decision making on an adequate critical appraisal of full articles.

This article is protected by copyright. All rights reserved 


\section{References}

Almaqrami, B. S., Hua, F., Liu, Y., \& He, H. (2020). Research waste-related editorial policies of leading dental journals: Situation 2018. Oral Diseases, 26, 696-706. doi:10.1111/odi.13257

Arunachalam, L., Hunter, I. A., \& Killeen, S. (2017). Reporting of Randomized Controlled Trials With Statistically Nonsignificant Primary Outcomes Published in High-impact Surgical Journals. Annals of Surgery, 265, 1141-1145. doi:10.1097/sla.0000000000001795

Austin, J., Smith, C., Natarajan, K., Som, M., Wayant, C., \& Vassar, M. (2019). Evaluation of spin within abstracts in obesity randomized clinical trials: A cross-sectional review. Clinical Obesity, 9, e12292. doi:10.1111/cob.12292

Boutron, I., Altman, D. G., Hopewell, S., Vera-Badillo, F., Tannock, I., \& Ravaud, P. (2014). Impact of spin in the abstracts of articles reporting results of randomized controlled trials in the field of cancer: the SPIIN randomized controlled trial. Journal of Clinical Oncology, 32, 4120-4126. doi:10.1200/JCO.2014.56.7503

Boutron, I., Dutton, S., Ravaud, P., \& Altman, D. G. (2010). Reporting and interpretation of randomized controlled trials with statistically nonsignificant results for primary outcomes. JAMA, 303, 2058-2064. doi:10.1001/jama.2010.651

Brignardello-Petersen, R., Carrasco-Labra, A., Glick, M., Guyatt, G. H., \& Azarpazhooh, A. (2014). A practical approach to evidence-based dentistry: understanding and applying the principles of EBD. Journal of American Dental Association, 145, 1105-1107. 
doi:10.14219/jada.2014.102

Brignardello-Petersen, R., Carrasco-Labra, A., Glick, M., Guyatt, G. H., \& Azarpazhooh, A. (2015). A practical approach to evidence-based dentistry: III: how to appraise and use an article about therapy. Journal of American Dental Association, 146, 42-49 e41. doi:10.1016/j.adaj.2014.11.010

Carrasco-Labra, A., Brignardello-Petersen, R., Azarpazhooh, A., Glick, M., \& Guyatt, G. H. (2015). A practical approach to evidence-based dentistry: X: How to avoid being misled by clinical studies' results in dentistry. Journal of American Dental Association, 146, 919-924. doi:10.1016/j.adaj.2015.08.008

Chen, Y., Hua, F., Mei, Y., Thiruvenkatachari, B., Riley, P., \& He, H. (2019). The Characteristics and Level of Evidence of Clinical Studies Published in 5 Leading Orthodontic Journals. Journal of Evidence Based Dental Practice, 19, 273-282. doi:https://doi.org/10.1016/j.jebdp.2019.03.001

Chiu, K., Grundy, Q., \& Bero, L. (2017). 'Spin' in published biomedical literature: A methodological systematic review. PLoS Biololy, 15, e2002173. doi:10.1371/journal.pbio.2002173

Cooper, C. M., Gray, H. M., Ross, A. E., Hamilton, T. A., Bea Downs, J., Wayant, C., \& Vassar, M. (2018). Evaluation of spin in the abstracts of otolaryngology randomized controlled trials. Laryngoscope, 2036-2040. doi:10.1002/lary.27750

Fang, X., Hua, F., Riley, P., Chen, F., Zhang, L., Walsh, T., \& Chen, Z. (2020). Abstracts of published randomised controlled trials in Endodontics: Reporting quality and spin. International Endodontic Journal. doi:10.1111/iej.13310

This article is protected by copyright. All rights reserved 
Fergusson, D. (2009). Inappropriate referencing in research. BMJ, 339, b2049. doi:10.1136/bmj.b2049

Garcovich, D., Ausina Marquez, V., \& Adobes Martin, M. (2020). The online attention to research in periodontology: An Altmetric study on the most discussed articles on the web. Journal of Clinical Periodontology, 47, 330-342. doi:10.1111/jcpe.13221

Greenberg, S. A. (2009). How citation distortions create unfounded authority: analysis of a citation network. BMJ, 339, b2680. doi:10.1136/bmj.b2680.

Haynes, R. B., Devereaux, P. J., \& Guyatt, G. H. (2002). Clinical expertise in the era of evidence-based medicine and patient choice. ACP Journal Club, 136, A11-14. doi:10.1136/ebm.7.2.36

Hopewell, S., Clarke, M., Moher, D., Wager, E., Middleton, P., Altman, D. G., Schulz, K. F., \& and the, C. G. (2008). CONSORT for Reporting Randomized Controlled Trials in Journal and Conference Abstracts: Explanation and Elaboration. PLOS Medicine, 5, e20. doi:10.1371/journal.pmed.0050020

Jellison, S., Roberts, W., Bowers, A., Combs, T., Beaman, J., Wayant, C., \& Vassar, M. (2019). Evaluation of spin in abstracts of papers in psychiatry and psychology journals. BMJ Evidence Based Medicine. doi:10.1136/bmjebm-2019-111176

Khan, M. S., Lateef, N., Siddiqi, T. J., Rehman, K. A., Alnaimat, S., Khan, S. U., Riaz, H., Murad, M. H., Mandrola, J., Doukky, R., \& Krasuski, R. A. (2019). Level and Prevalence of Spin in Published Cardiovascular Randomized Clinical Trial Reports With Statistically Nonsignificant Primary Outcomes: A Systematic Review. JAMA Network Open, 2, 
e192622. doi:10.1001/jamanetworkopen.2019.2622

Kinder, N. C., Weaver, M. D., Wayant, C., \& Vassar, M. (2019). Presence of 'spin' in the abstracts and titles of anaesthesiology randomised controlled trials. British Journal of Anaesthesia, 122, e13-e14. doi:10.1016/j.bja.2018.10.023

Kiriakou, J., Pandis, N., Madianos, P., \& Polychronopoulou, A. (2014). Assessing the Reporting Quality in Abstracts of Randomized Controlled Trials in Leading Journals of Oral Implantology. Journal of Evidence Based Dental Practice, 14, 9-15. doi:https://doi.org/10.1016/j.jebdp.2013.10.018

Kloukos, D., Papageorgiou, S. N., Doulis, I., Petridis, H., \& Pandis, N. (2015). Reporting quality of randomised controlled trials published in prosthodontic and implantology journals. Journal of Oral Rehabilitation, 42, 914-925. doi:10.1111/joor.12325

Kumar, S., Mohammad, H., Vora, H., \& Kar, K. (2018). Reporting Quality of Randomized Controlled Trials of Periodontal Diseases in Journal Abstracts-A Cross-sectional Survey and Bibliometric Analysis. Journal of Evidence Based Dental Practice, 18, 130-141.e122. doi:10.1016/j.jebdp.2017.08.005

Lieber, R., Pandis, N., \& Faggion, C. M., Jr. (2020). Reporting and handling of incomplete outcome data in implant dentistry: A survey of randomized clinical trials. Journal of Clinical Periodontology, 47, 257-266. doi:10.1111/jcpe.13222

Moher, D., Schulz, K. F., \& Altman, D. G. (2001). The CONSORT statement: revised recommendations for improving the quality of reports of parallel-group randomised trials. The Lancet, 357, 1191-1194. doi:https://doi.org/10.1016/S0140-6736(00)04337-3

This article is protected by copyright. All rights reserved 
Roszhart, J. I., Kumar, S. S., Allareddy, V., Childs, C. A., \& Elangovan, S. (2019). Spin in abstracts of randomized controlled trials in dentistry: A cross-sectional analysis. Journal of American Dental Association. doi:10.1016/j.adaj.2019.08.009

Sendyk, D. I., Rovai, E. S., Souza, N. V., Deboni, M. C. Z., \& Pannuti, C. M. (2019). Selective outcome reporting in randomized clinical trials of dental implants. Journal of Clinical Periodontology, 46, 758-765. doi:10.1111/jcpe.13128

Symonds, Q. (2020 March 3). QS World University Rankings for Dentistry 2020. Retrieved from https://www.qschina.cn/en/university-rankings/university-subject-rankings/2020/dentist ry

Warren, V. T., Patel, B., \& Boyd, C. J. (2019). Analyzing the relationship between Altmetric score and literature citations in the Implantology literature. Clinical Implant Dentistry and Related Research. doi:10.1111/cid.12876

This article is protected by copyright. All rights reserved 
Table 1 Characteristics of included RCT abstracts $(\mathrm{N}=196)$

Number of

\section{Characteristics}

abstracts $\mathrm{n}(\%)$

\begin{tabular}{ll} 
Journal & $34(17.3)$ \\
COIR & $30(15.3)$ \\
CIDRR & $23(11.7)$ \\
IJOI & $18(9.2)$ \\
JCP & $14(7.1)$ \\
JOP & $77(39.3)$ \\
Others & \\
\hline Topic & $49(25.0)$ \\
\hline Periodontology & $147(75.0)$ \\
\hline Oral Implantology &
\end{tabular}

\begin{tabular}{ll} 
Geographic origin & $98(50.0)$ \\
Europe & $55(28.1)$ \\
Asia & $38(19.4)$ \\
America & $5(2.6)$ \\
Others & \\
\hline Type of institution & $184(93.9)$
\end{tabular}

This article is protected by copyright. All rights reserved 


\begin{tabular}{|c|c|}
\hline Others & $12(6.1)$ \\
\hline \multicolumn{2}{|l|}{ Top dental schools } \\
\hline Yes & $47(24.0)$ \\
\hline No & $149(76.0)$ \\
\hline \multicolumn{2}{|l|}{ Multiple affiliations } \\
\hline Yes & $125(63.8)$ \\
\hline No & $71(36.2)$ \\
\hline \multicolumn{2}{|l|}{ International collaboration } \\
\hline Yes & $60(30.6)$ \\
\hline No & $136(69.4)$ \\
\hline \multicolumn{2}{|l|}{ Funding status } \\
\hline Funded by industry & $79(40.3)$ \\
\hline Funded by other sources & $52(26.5)$ \\
\hline Unfunded/unreported & $65(33.2)$ \\
\hline \multicolumn{2}{|l|}{ Centers } \\
\hline Single center & $172(87.8)$ \\
\hline Multi-centers & $24(12.2)$ \\
\hline \multicolumn{2}{|l|}{ Treatment arms } \\
\hline Two arms & $179(91.3)$ \\
\hline$\geq$ three arms & $17(8.7)$ \\
\hline
\end{tabular}

This article is protected by copyright. All rights reserved 
Total

$196(100.0)$

COIR=Clinical Oral Implants Research, CIDRR=Clinical Implant Dentistry and Related Research,

IJOI=International Journal of Oral Implantology, JCP=Journal of Clinical Periodontology, JOP=Journal of Periodontology.
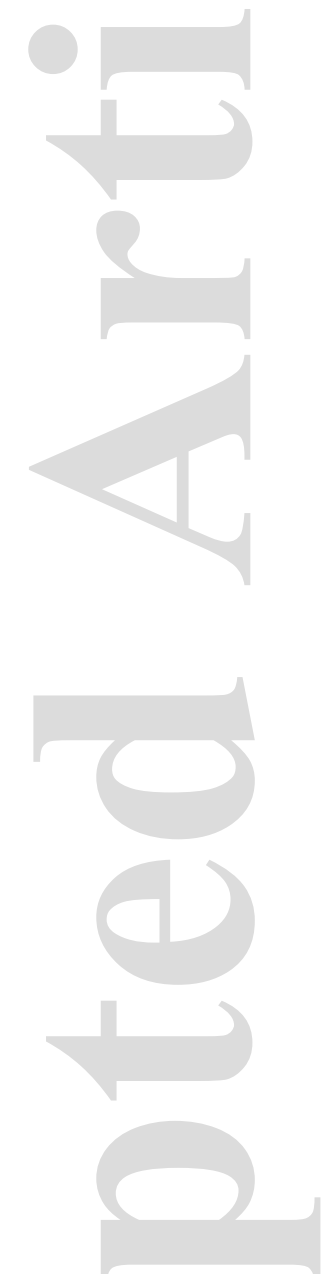

This article is protected by copyright. All rights reserved 
Table 2 Categories of spin strategies in the Results and Conclusion Section ( $N=196)$ (Boutron et al., 2011)

\begin{tabular}{lc} 
Spin strategies in the Results Section & $\mathbf{n}(\mathbf{\%})$ \\
\hline Focusing on significant within-group comparisons for primary outcomes & $15(7.7)$ \\
Focusing on significant within- and/or between-group secondary outcomes & $32(16.3)$ \\
Focusing on significant subgroup analyses & $8(4.1)$ \\
Focus on a statistically significant primary endpoint with the omission of one or & $8(4.1)$ \\
\end{tabular}

Claiming equivalence or non-inferiority for statistically non-significant results

outcome

Focusing only on statistically significant between-group results for other primary

outcomes, secondary outcomes or subgroup analyses

Acknowledge statistically non-significant results for the primary outcome but

emphasize the beneficial effect of treatment

Acknowledge statistically non-significant results for the primary outcome but

emphasize other statistically significant results

Conclusion focusing on within-group assessment

This article is protected by copyright. All rights reserved 
Table 3 Association between study characteristics, presence of spin ( $N=196)$, and severity of spin ( $N=137)$ in multivariable logistic regression model

\begin{tabular}{|c|c|c|c|c|}
\hline \multirow{2}{*}{ Characteristics } & \multicolumn{2}{|l|}{ Presence of spin } & \multicolumn{2}{|l|}{ Severity of spin } \\
\hline & OR $(95 \% \mathrm{Cl})$ & $p$ value ${ }^{a}$ & OR $(95 \% \mathrm{Cl})$ & $p$ value $^{a}$ \\
\hline \multicolumn{5}{|l|}{ Topic } \\
\hline Periodontology & reference & & reference & \\
\hline Oral implantology & $0.73(0.34,1.59)$ & 0.427 & $0.24(0.08,0.70)$ & 0.009 \\
\hline \multicolumn{5}{|l|}{ Top dental schools } \\
\hline No & reference & & reference & \\
\hline Yes & $0.91(0.42,1.97)$ & 0.812 & $1.25(0.33,4.72)$ & 0.740 \\
\hline \multicolumn{5}{|l|}{ International collaboration } \\
\hline No & reference & & reference & \\
\hline Yes & $1.25(0.60,2.59)$ & 0.552 & $1.17(0.36,3.82)$ & 0.791 \\
\hline \multicolumn{5}{|l|}{ Funding status } \\
\hline Funded by industry & reference & & reference & \\
\hline Funded by other sources & $0.81(0.38,1.74)$ & 0.592 & $1.53(0.38,6.12)$ & 0.548 \\
\hline Unfunded/unreported & $0.86(0.37,1.99)$ & 0.724 & $1.84(0.48,7.03)$ & 0.373 \\
\hline \multicolumn{5}{|l|}{ Centers } \\
\hline Single center & reference & & reference & \\
\hline Multi-centers & $0.28(0.11,0.73)$ & 0.009 & $0.98(0.10,9.91)$ & 0.988 \\
\hline
\end{tabular}




\section{Figure legend}

Figure 1 Flow diagram of study selection.

This article is protected by copyright. All rights reserved 


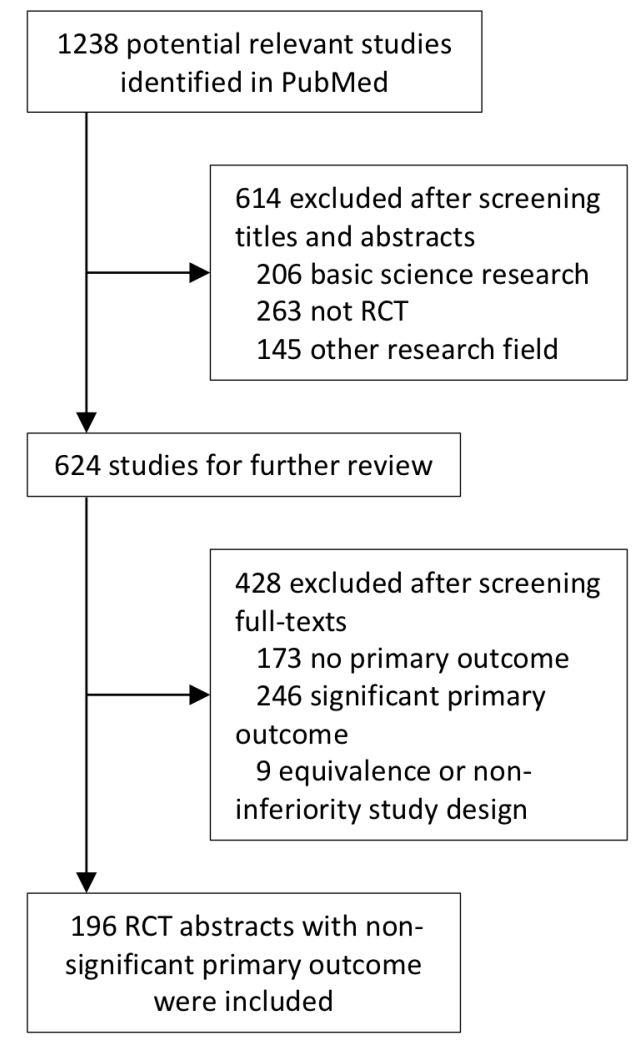

jcpe_13340_f1.tiff 